\title{
Instrumental aversive conditioning in newly hatched domestic chicks'
}

JAMES F, ZOLMAN, UNIVERSITY OF KENTUCKY MEDICAL CENTER R. CHRIS MARTIN, HOLLINS COLLEGE

The performance of forty chicks in a straight runway to heat reinforcement was measured under four drive conditions across 20 trials in $a 2$ by 2 by 20 factorial design. The two main treatment conditions were level of ambient temperature and length of time in the cold start box before a trial began. Heat was a potent reinforcement for newly hatched chicks as demonstrated by significant increases in starting, alley, and total speed scores across trials. Manipulations in drive level also significantly affected both the rate of acquisition and the asymptotic level of performance.

Behavioral studies with newly hatched chicks have been beset with many problems. One of the most important has been the lack of a reliable reinforcement for very young birds (one to three days old). The traditional reinforcers, such as food and water, exert little control over newly hatched chicks, as they require no food or water for approximately the first $48 \mathrm{~h}$. Thus, most of the studies of behavior of the newly hatched chick have been on imprinting. Most imprinting experiments, however, have been plagued with large within-group variance, and only a few studies have reported reliable differences with small numbers of Ss (Sluckin, 1965, pp. 31-32).

The problems with traditional reinforcers led to the choice of heat as reinforcement in this study. It is well known that chicks will seek warmth (Collias, 1952), but the relevant stimulus parameters of heat as reinforcement for them have not been determined. In this study the reinforcement value of a constant amount of heat was determined under four drive conditions.

\section{Subjects}

The Ss were 40 Arbor Acre $x$ Vantress chicks obtained from a commercial hatchery 20 h after hatching. On receipt from the hatchery the chicks were placed in communal cages of a lighted $35^{\circ} \mathrm{C}$ brooder with food and water available ad lib.

\section{Apparatts}

The apparatus was a straight runway divided into a start box, alley, and goal box by two guillotine doors 9 in. from the ends. The entire apparatus was painted flat gray, and had an open top. The width (5-3/4 in.) and depth (8-1/2 in.) were the same for all parts of the apparatus. The runway was 68 in. long. A raised 1 in. false floor of $1 / 4 \mathrm{in.} \mathrm{hardware}$ cloth extended the length of the apparatus. The runway and goal box were illuminated by a $4 \mathrm{ft}, 40-W$ fluorescent bulb located $2 \mathrm{ft}$ above the alley floor and by two 18 in., 15-W fluorescent bulbs $2 \mathrm{ft}$ above the goal box floor. Photoelectric cells located 3 in. in front of the start and goal boxes were connected to a Standard Electric timer and were used to re- cord runway latencies to the nearest .01 sec. Start time was obtained with a stopwatch. Heat reinforcement was delivered by a 250-W, 115-V, red bulb infrared heat lamp located 16 in. above the floor of the goal box. The duration of the heat was controlled by a preset Universal timer that was activated by a hand switch at the moment $S$ entered the goal box. During the intertrial interval $S s$ were held in an enclosed $35^{\circ} \mathrm{C}$ box $(6 \times 6) \times 6$ in.). All Ss were run in a Tyler temperature control room (12 $\times 7 \times 7 \mathrm{ft})$ with a fan providing masking noise. The temperature of the cold room was controlled by a thermostat (sensitivity $2^{\circ} \mathrm{C}$ ) and monitored by a Bristol recording thermometer located outside the room.

\section{Procedure}

The two main treatment conditions were level of ambient temperature and length of time in the start box before a trial began. Two levels of each of these conditions yielded a 2 by 2 factorial design. The ambient temperature levels were $0^{\circ} \mathrm{C}$ and $14^{\circ} \mathrm{C}$ with either $10 \mathrm{sec}$ holding in the cold start box or no holding in the start box before a trial. All Ss were tested within 24 to $56 \mathrm{~h}$ after hatching, with the age of Ss equated across groups.

The experiment consisted of two stages, pretraining and acquisition. Pretraining consisted of five trials in which the chicks were shaped to approach the goal box and heat from successively increasing distances (directly in front of the goal box, 1/4 of the distance of the alley, and from the middle of the alley). Length of exposure to heat was 15 sec during pretraining trials. Training trials began $30 \mathrm{sec}$ after the pretraining trials. On a training trial the bird was placed into the start box, the start box door was opened either immediately or 10 sec later, and start time and alley time were recorded on each trial. Start time was the latency with which the bird left the start box and interrupted the first photocell beam (a distance of 6 in.). Alley time was the latency from the first photocell to the second photocell (a distance of 44 in.). All birds received 20 acquisition trials with 5 sec exposure to heat as reinforcement. The intertrial interval of $30 \mathrm{sec}$ was maintained throughout the 20 trials.

\section{Results}

All time scores were converted into speed scores in $\mathrm{ft}$ per sec. All groups showed increases in starting speed scores over the 20 trials, with the $14^{\circ} \mathrm{C}-$ No Holding group slower than any of the other groups. Analysis of variance of starting speed scores showed a significant Holding effect $(F=5.33, \mathrm{df}=1 / 36, \mathrm{p}<.05)$ and a significant Trials effect $(F=7.00, d f=19 / 684, p<.001)$. The mean alley speeds of the four groups over 


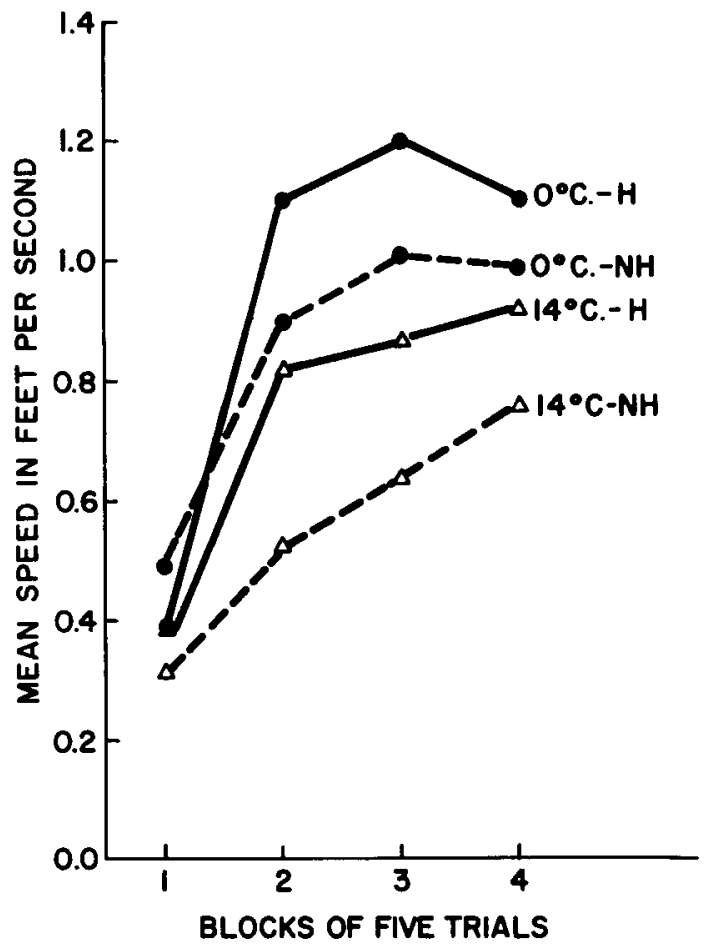

Fig. 1. Mean alley speed scores across blocks of five trials for $0^{\circ} \mathrm{C}-$ and $14^{\circ} \mathrm{C}-$ Holding (H) and No-Holding (NH) groups.

blocks of five trials are presented in Fig. 1. The $0^{\circ} \mathrm{C}$-Holding group was faster on the last fifteen trials than any of the other groups. Second fastest was the $0^{\circ} \mathrm{C}-\mathrm{No}$ Holding group, followed by the $14^{\circ} \mathrm{C}$ -Holding group. The $14^{\circ} \mathrm{C}-\mathrm{No}$ Holding group was slower than all the other groups at every point. Analysis of variance of these data showed a significant Temperature effect $(F=5.57, d f=1 / 36, p<.05)$, and a significant Trials effect $(F=13.71$, df $=19 / 684$, $p<.001)$. There was no significant Trials by Holding interaction nor Trials by Temperature interaction when all 20 trials were considered. The analysis of pre-asymptotic performance (the first 10 trials) showed a significant Trials by Temperature ( $F=2.17$, df $=9 / 324, p<.05)$ and Trials by Holding effect $(F=2.67$, $\mathrm{df}=9 / 324, \mathrm{p}<.005)$.

Start time plus alley time yielded total time. For total speed the greatest differences among the groups occurred during the first 10 trials before asymptotic performance was attained. The order of the groups in total speed scores followed the same relationship as shown in Fig. 1. Analysis of variance of speed scores over all 20 trials showed a significant Temperature effect $(F=5.42, \mathrm{df}=1 / 36, \mathrm{p}<.05$ ) and a significant Trials effect $(F=16.01, d f=9 / 324, p<.001)$. Discussion

The results show that heat is a potent reinforcement for newly hatched chicks as demonstrated by the significant increase in speed across trials for the three measures. Ambient temperature and detention in the start box also significantly affected behavior. Of these two treatment conditions, the level of ambient temperature had a greater effect on behavior than detention in the start box. These manipulations are assumed to affect drive level, and thus higher drive levels result in both faster and higher asymptotic levels of performance. However, since the duration and amount of heat were constant for each group but drive levels varied, the performance differences might also have been caused by difference in magnitude of reward (cf., Woods, Davidson, \& Peters, 1964).

The fact that heat can play such a significant role in the behavior of young chicks emphasizes some of the problems related to tests involving young birds. In addition, the finding that both rate and asymptotic levels of performance differed as a function of drive level over trials (e.g., first 10 trials in Fig. 1) provides further support for the assumption of a multiplicative relationship between Drive (D) and Habit Strength ( $\left.\mathrm{g}^{\mathrm{H}} \mathrm{r}\right)$ (cf., Brown, 1961, p. 134).

A review of the literature regarding imprinting and perceptual learning of young birds reveals that the ambient temperature has not usually been reported. Presumably, the ambient temperature in these studies was not rigidly controlled (cf., Sluckin, 1965). The large within-group variability found in many imprinting studies may be due to fluctuations in ambient temperature during the typical three to five day span in which the birds are tested. Also, nonspecific arousal differences caused by different testing ambient temperatures could account for some of the variability observed between imprinting studies. The important implications of heat as reinforcement for the newly hatched chick should lead to stricter control of this variable in future experiments. Besides being a potent reinforcement, the use of heat has other advantages for behavioral testing of young birds. For example, Ss may be run repeatedly in a behavioral situation without satiation to the UCS, thereby making many massed trials possible. The ability to administer numerous trials may be of prime importance when such concepts as critical periods are involved.

\section{References}

Brown, J. S. Motivation of behavior. New York: McGraw-Hill Co., 1961.

Collias, N. E. The development of social behavior in birds. Auk, $1952,69,127-159$.

Sluckin, W. Imprinting and early learning. Chicago: Aldine Co., 1965.

Woods, P. J., Davidson, E. H., \& Peters, R. J., Jr. Instrumental escape conditioning in a water tank: effects of variations in drive stimulus intensity and reinforcement magnitude. J. comp. physiol. Psychol., 1964, 57, 466-470.

\section{Hote}

1. This research was supported by the Human Development Studies Program of the College of Medicine, University of Kentucky with funds granted by the Foundations' Fund for Research in Psychiatry. The authors wish to thank $P$. J. Woods for his critical reading of the manuscript and Helen Grierson for her assistance in data collection and analysis. 